\title{
Perceptions of Hospital Pharmacists Concerning Clinical Research: A Survey Study
}

\author{
Robin Lee, Karen Dahri, Tim T Y Lau, and Stephen Shalansky
}

\begin{abstract}
Background: Few studies have attempted to determine the proportion of Canadian hospital pharmacists involved in clinical research, despite a general consensus that research should be an essential component of a pharmacist's professional role.

Objectives: The primary objective was to characterize the involvement in clinical pharmacy research of hospital pharmacists in the 4 health authorities of the Lower Mainland of British Columbia (collectively known as the Lower Mainland Pharmacy Services). The secondary objective was to identify perceived barriers to conducting research.

Methods: Pharmacists employed within Lower Mainland Pharmacy Services were invited to participate in an online cross-sectional survey, for completion in August and September 2015. Descriptive statistics were used to analyze the results. Groups of survey participants were compared to examine differences in measured outcomes.

Results: A total of 534 pharmacists were surveyed, with a response rate of $16 \%$ (85/534). Overall, $77 \%$ (55/71) of the respondents reported having participated in research, and 87\% (62/71) expressed interest in conducting future research. Chart reviews $(78 \%, 36 / 46)$ and surveys $(41 \%, 19 / 46)$ were the most common study designs used in prior research. Participants self-identified their research-related strengths as literature evaluation $(46 \%, 27 / 59)$ and hypothesis generation $(44 \%$, 26/59). Conversely, $81 \%$ (48/59) of respondents self-identified statistical analysis as a weakness. Most respondents stated that personal satisfaction $(82 \%, 49 / 60)$ and the opportunity to learn about disease states $(78 \%$, $47 / 60)$ were the driving factors for conducting research. The most commonly cited barrier to conducting research was lack of time (92\%, $55 / 60)$. Opportunities to join existing teams $(73 \%, 44 / 60)$ and mentorship programs $(70 \%, 42 / 60)$ were identified as the most popular arrangements for encouraging future research.
\end{abstract}

Conclusions: Most of the pharmacists who responded to this survey reported having participated in clinical pharmacy research, but a lack of dedicated time appears to be a major hurdle to greater research participation. A targeted program increasing exposure to existing research teams and mentorship opportunities is recommended for promoting future research.

Keywords: clinical research, pharmacist, barriers, strengths, weaknesses, survey

\section{RÉSUMÉ}

Contexte : Peu d'études ont cherché à déterminer la proportion de "pharmaciens d'hôpitaux canadiens qui contribuent à la recherche clinique, et ce, malgré un consensus voulant que la recherche doive être un élément essentiel du rôle professionnel des pharmaciens.

Objectifs : L'objectif principal était d'offrir un portrait de la contribution à la recherche sur la pharmacie clinique des pharmaciens d'hôpitaux des quatre régies régionales des basses-terres continentales de la ColombieBritannique (appelées collectivement Lower Mainland Pharmacy Services, c.-à-d. services de pharmacie des basses-terres continentales). L'objectif secondaire était de recenser les éléments perçus comme des obstacles à la réalisation de recherches.

Méthodes : Les pharmaciens employés au sein des services de pharmacie des basses-terres continentales ont été invités à participer par voie électronique à une enquête transversale qui devait être complétée en août et en septembre 2015. Des statistiques descriptives ont été employées pour analyser les résultats. On a aussi comparé des groupes de participants à l'enquête afin d'examiner les différences entre les résultats mesurés.

Résultats : Au total, 534 pharmaciens ont été sondés et le taux de réponse était de $16 \%$ (85/534). Dans l'ensemble, $77 \%$ (55/71) des répondants indiquaient avoir participé à des recherches et $87 \%$ (62/71) souhaitaient faire de la recherche dans l'avenir. L'analyse de dossiers médicaux (78 \%, 36/46) et les sondages ( $41 \%, 19 / 46)$ représentaient les plans d'étude les plus utilisés par les répondants au cours de recherches antérieures. Les participants ont indiqué que leurs forces en lien avec la recherche étaient leur capacité d'évaluer la littérature $(46 \%, 27 / 59)$ et de formuler des hypothèses $(44 \%, 26 / 59)$. En revanche, $81 \%$ (48/59) ont signalé l'analyse statistique comme leur point faible. La plupart des répondants croyaient que la satisfaction personnelle $(82 \%, 49 / 60)$ et la perspective d'acquérir des connaissances sur les maladies $(78 \%, 47 / 60)$ représentaient les principaux facteurs les motivant à faire de la recherche. Ce qui était évoqué le plus souvent comme un obstacle à la recherche était le manque de temps $(92 \%, 55 / 60)$. Les occasions de se joindre à des équipes en place (73 \%, 44/60) et les programmes de mentorat $(70 \%, 42 / 60)$ ont été désignés comme les dispositions les plus attrayantes pour encourager à poursuivre de futures recherches.

Conclusions : La plupart des pharmaciens ayant répondu au sondage ont indiqué avoir contribué à des recherches en pharmacie clinique, mais le manque de temps réservé pour la recherche semblait être un obstacle important à une plus grande participation aux activités de recherche. Un programme ciblé multipliant les possibilités de fréquenter des équipes de recherche déjà établies et offrant plus d'occasions de mentorat serait une façon de promouvoir de futures recherches.

Mots clés : recherche clinique, pharmacien, obstacles, forces, faiblesses, enquête 


\section{INTRODUCTION}

Cinical pharmacy research is important for advancing the pharmacy profession; however, there is limited information in the literature regarding current perceptions, barriers, and competencies related to pharmacy research. ${ }^{1}$ Pharmacists have previously identified research as one of their professional responsibilities and an essential activity for improving patient care. ${ }^{2-7}$ One study reported that $96 \%$ of pharmacists surveyed considered research to be an important factor in improving care, and $80 \%$ expressed a desire to be more involved in research. ${ }^{1}$ Although pharmacists' interest in conducting research is high, current levels of research participation remain low, at about $30 \%$ to $50 \%$. ${ }^{1,2,6-8}$ High levels of interest combined with a low level of participation indicate a need to identify impediments to research that exist in the workplace, as well as the educational approaches that could be employed to increase participation.

Previous studies have identified several barriers to conducting research, such as lack of time and lack of reimbursement. ${ }^{2,8,9,10}$ Some key competencies have also been shown to be necessary for pharmacists to conduct clinical pharmacy research, including literature review and evaluation, hypothesis generation, study design, and research methods. ${ }^{11-13}$ Although these fundamental skills have been identified as essential, the extent of training that pharmacists have received in these areas has not been quantified.

One of the strategic goals of the Lower Mainland Pharmacy Services in British Columbia is to double the annual rate of research activity. The objective of the study reported here was to survey hospital pharmacists within the Lower Mainland Pharmacy Services to identify their current level of research activity and barriers that prevent them from conducting research. The findings from this survey will be used to develop a targeted initiative to advance the research-related skills of the organization's pharmacy staff, with the hope of increasing the rate of research activity within the region.

\section{METHODS}

\section{Design}

This cross-sectional survey targeted hospital pharmacists in the Lower Mainland's 4 health authorities, which include 26 hospitals. The study was approved by the Behavioural Research Ethics Board at the University of British Columbia, and informed consent was obtained from all participants.

\section{Study Population}

All hospital pharmacists were eligible to participate, regardless of the level of advanced training that they had completed beyond their initial pharmacy degree; nonpharmacist staff were excluded. A total of 534 pharmacists were identified for initial contact. Potential survey participants were contacted via e-mail using the health authorities' e-mail group lists.

\section{Sampling Method}

An invitation to participate in this study, which included a link to the online survey, was sent by e-mail to all pharmacists employed by the 4 health authorities. To preserve anonymity, no identifying information was collected from participants. Two weeks after the initial invitation, a reminder was sent by e-mail.

\section{Intervention}

The online survey was administered using the survey platform FluidSurveys (http://fluidsurveys.com/). The survey questions were based on articles identified in a comprehensive literature search of MEDLINE and Embase, as well as articles identified by reviewing the reference lists of selected articles and input from stakeholders. The survey was trialled with 6 pharmacists, and the questions were reworded, reorganized, or further explained as necessary to improve clarity.

The survey contained 7 major sections: baseline information (6 multiple-choice and open-answer questions); participation in previous projects ( 2 yes/no questions); perceptions about research (18 open-response [e.g., numeric response], multiple-choice, and yes/no questions); strengths and weaknesses in conducting research (2 multiple-choice questions); factors, barriers, and benefits to conducting research (3 multiple-choice questions); strategies to promote research (1 multiple-choice question); and additional comments (1 multiple-choice question). Survey questions used in the study are listed in Appendix 1 (available at https:/www.cjhp-online.ca/index.php/cjhp/issue/view/126/ showToc).

On the basis of their responses to questions about previous research experiences and interest in future projects, respondents were separated into 4 groups: those who had participated in or conducted previous research and were interested in future research, those who had participated in or conducted research but were not interested in future research, those who had not participated in or conducted previous research but were interested in future research, and those who had not participated in or conducted previous research and were not interested in future research. Respondents saw only those questions pertinent to their own group; they could not view questions directed to the other groups. The survey flow is outlined in Appendix 2 (available at https://www.cjhp-online.ca/index.php/cjhp/issue/view/ 126/showToc).

One month was allowed for the survey to be completed after the initial e-mail invitation was sent. The survey was conducted in August and September 2015.

\section{Statistical Analysis}

All survey responses were included in the analysis of the data. Aggregate survey data were downloaded from the survey website and coded into a password-protected spreadsheet (Excel 2013 for 
Windows, Microsoft Corporation). The survey responses were manually reviewed by one of the investigators (R.L.) in the spreadsheet and verified with the primary investigator (K.D.) before analyses were performed. Descriptive statistical analyses were employed. All statistical analyses were performed in the spreadsheet software.

\section{RESULTS}

\section{Demographic Characteristics}

A total of 534 pharmacists were invited to participate, and 85 (16\%) submitted responses (Figure 1); however, some participants did not answer every question. Both complete and incomplete survey responses were included in the analysis. Each question was analyzed according to responses submitted, and denominators were adjusted as appropriate to reflect the number of respondents.

Baseline demographic characteristics of the survey respondents are presented in Table 1 . The highest level of training was most commonly a hospital residency program $(52 \%, 37 / 71)$, followed by a postgraduate PharmD program $(31 \%, 22 / 71)$. Survey participants had worked in a pharmacy for a median of 10 years (interquartile range [IQR] 4-20 years), with a median of 11 years (IQR 4-22 years) of pharmacy practice experience across a wide range of practice settings. Overall, $85 \%$ (60/71) of participants self-identified as being "moderately experienced" with research, 7\% (5/71) of participants identified as being "experienced", and 8\% (6/71) identified as being "inexperienced" (no experience with any research projects). The majority of respondents $(77 \%, 55 / 71)$ had participated in previous research projects, and $87 \%(62 / 71)$ were interested in participating in future projects.

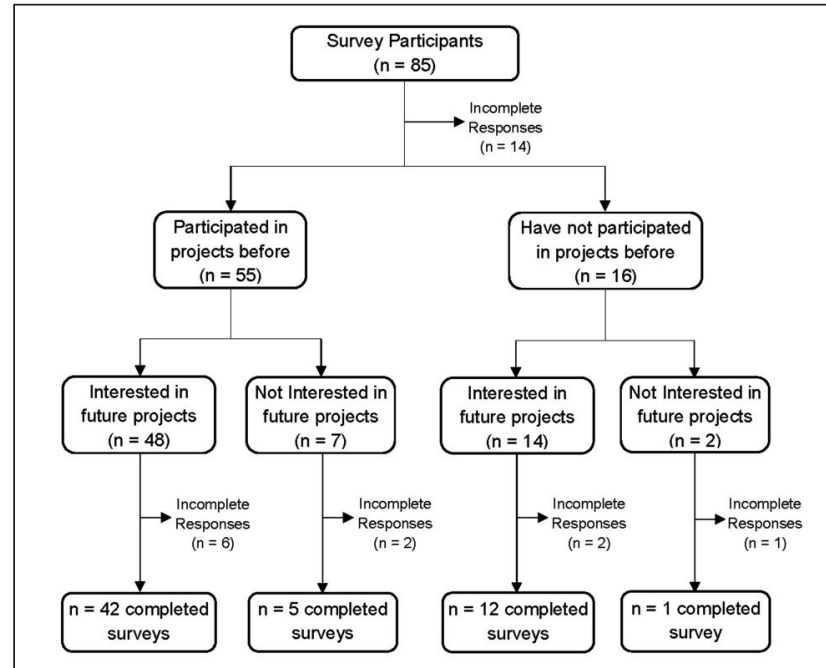

Figure 1. Study flow chart. Participants were divided into 4 groups according to their survey responses concerning previous research experience and interest in future research.

\section{Pharmacists' Involvement in Research}

Information about respondents' research involvement and publication experience is presented in Table 2. Survey respondents with recent research experience had participated in a median of 3 projects (IQR $1-4.5$ projects) within the past 5 years. The most common research-related tasks performed by respondents were data analysis $(64 \%, 30 / 47)$ and presentation of study findings $(66 \%, 31 / 47)$. Most respondents reported having completed both of these tasks 1-3 times within the past 5 years. Of respondents who had participated in research, the majority $(81 \%, 38 / 47)$ had not applied for grant funding for their projects. The most popular dissemination activity was poster presentations $(72 \%, 34 / 47)$,

\section{Table 1. Demographic Characteristics of Study Participants}

\begin{tabular}{|c|c|c|}
\hline \multirow{2}{*}{$\begin{array}{l}\text { Characteristic } \\
\text { Current position }\end{array}$} & \multicolumn{2}{|c|}{$\begin{array}{c}\text { No. (\%) of Participants* } \\
(n=71)\end{array}$} \\
\hline & & \\
\hline Clinical pharmacist & 28 & (39) \\
\hline Clinical pharmacy specialist & 18 & (25) \\
\hline Clinical coordinator & 8 & (11) \\
\hline Dispensary pharmacist & 4 & (6) \\
\hline Clinical supervisor & 3 & (4) \\
\hline Other & 10 & (14) \\
\hline Time worked in pharmacy (years) (median and IQR) & 10 & $(4-20)$ \\
\hline Time in practice (years) (median and IQR) & 11 & $(4-22)$ \\
\hline \multicolumn{3}{|l|}{ Highest level of education } \\
\hline Residency & 37 & (52) \\
\hline Postgraduate PharmD & 22 & (31) \\
\hline Bachelor's degree in pharmacy (BScPharm) & 7 & (10) \\
\hline Fellowship & 2 & (3) \\
\hline PhD & 1 & (1) \\
\hline Other & 2 & (3) \\
\hline
\end{tabular}


Table 2. Research and Publication Experience of Respondents Who Reported Having Conducted Research in the 5 Years Preceding the Survey

\begin{tabular}{|c|c|c|c|c|c|c|}
\hline Participant's Experience & \multicolumn{6}{|c|}{ No. (\%) of Participants* } \\
\hline Projects in past 5 years & \multicolumn{6}{|c|}{$n=47$} \\
\hline Total no. of projects (any role) (median and IQR) & \multicolumn{6}{|c|}{$3(1-4.5)$} \\
\hline As primary co-investigator (median and IQR) & \multicolumn{6}{|c|}{$1 \quad(0-2)$} \\
\hline As co-investigator (median and IQR) & \multicolumn{6}{|c|}{$2 \quad(0-3)$} \\
\hline Specific activity $(n=47) \dagger$ & \multicolumn{2}{|c|}{ None } & \multicolumn{2}{|c|}{$1-3$ times } & \multicolumn{2}{|c|}{$>3$ times } \\
\hline Development of research protocol & 18 & (38) & 19 & $(40)$ & 10 & $(21)$ \\
\hline Apply for grant funding & 38 & (81) & 9 & (19) & 0 & (0) \\
\hline Perform data analysis & 17 & (36) & 22 & (47) & 8 & $(17)$ \\
\hline Present study findings & 16 & (34) & 26 & (55) & 5 & $(11)$ \\
\hline Publish study findings & 22 & (47) & 20 & (43) & 5 & $(11)$ \\
\hline Studies conducted in the past & \multicolumn{6}{|c|}{$n=46$} \\
\hline Chart review & & & 36 & (78) & & \\
\hline Survey & & & 19 & (41) & & \\
\hline Controlled clinical trial & & & 9 & (20) & & \\
\hline Case-control or cohort study & & & 9 & (20) & & \\
\hline Focus group or qualitative research study & & & 8 & (17) & & \\
\hline Other & & & 14 & (30) & & \\
\hline
\end{tabular}

followed by publication of journal articles $(62 \%, 29 / 47)$ and podium presentations $(47 \%, 22 / 47)$.

The most common type of studies completed were chart reviews $(78 \%, 36 / 46)$, and the least common types were focus group and qualitative studies $(17 \%, 8 / 46)$. The majority of respondents had conducted research for personal interests (80\%, 37/46) and as part of their job requirements (52\%, 24/46).

Eighty percent $(47 / 59)$ of respondents were interested in conducting chart reviews in the future, and 49\% (29/59) were interested in conducting survey studies. Within the subset of respondents without previous research experience, there was a high degree of interest in controlled clinical trials $(85 \%, 11 / 13)$.

\section{Self-Identification of Research Strengths and Weaknesses}

The following strengths related to the research process were reported by just under half of respondents: extracting, critiquing, and evaluating scientific evidence from the literature $(46 \%$, 27/59); hypothesis generation $(44 \%, 26 / 59)$; and conduct of the study (41\%, 24/59). Eighty-one percent (48/59) of participants reported that their skills were weakest in statistical data analysis.

\section{Barriers, Factors, Benefits, and Strategies to Continuing Research}

Details regarding barriers to conducting research, as well as supporting factors, benefits, and strategies for conducting research in the future are presented in Table 3. Most respondents identified a lack of dedicated time $(92 \%, 55 / 60)$ and competing workload priorities $(88 \%, 53 / 60)$ as major barriers to conducting research, with a smaller proportion $(42 \%, 25 / 60)$ identifying a lack of support from management as a barrier. Factors cited as favourable to conducting research included increased personal satisfaction $(82 \%, 49 / 60)$ and increased opportunity to learn about a disease state $(78 \%, 47 / 60)$. More than $85 \%$ of respondents cited improvements in existing knowledge and filling knowledge gaps as the greatest benefits to conducting research. Opportunities to join existing teams $(73 \%, 44 / 60)$ and mentorship programs (70\%, 42/60) were identified as the most popular strategies for promoting future research.

\section{DISCUSSION}

Pharmacy research is essential to the advancement of pharmacy practice and the optimization of patient outcomes. Although this study provides evidence that pharmacists continue to recognize the value of research and are interested in becoming involved in future research, it also documents the persistence of barriers and challenges.

In this study, participants had higher levels of experience developing study protocols, analyzing study data, and presenting study findings and lower levels of applying for study grant funding than was reported in a survey of Canadian critical care pharmacists. ${ }^{1}$ Participants in the current study without prior research experience expressed strong interest in becoming involved in controlled clinical trials, which may reflect a lack of appreciation of and knowledge about the complexities involved in conducting this type of study.

The majority of survey respondents who reported being moderately experienced in research declared a weakness in statistical analysis and experimental design. Continued emphasis on and additional support for developing statistical analysis skills 
This single copy is for your personal, non-commercial use only.

For permission to reprint multiple copies or to order presentation-ready copies for distribution, contact CHHP at publications@cshp.ca

\section{Table 3. Barriers, Supporting Factors, Benefits, and Strategies for Conducting Research}

\begin{tabular}{|c|c|c|}
\hline \multirow{2}{*}{$\begin{array}{l}\text { Element } \\
\text { Barriers }\end{array}$} & \multicolumn{2}{|c|}{$\begin{array}{l}\text { No. }(\%) \text { of Respondents* } \\
\qquad(n=60)\end{array}$} \\
\hline & & \\
\hline Lack of dedicated time & 55 & $(92)$ \\
\hline Competing priorities with workload & 53 & (88) \\
\hline Lack of resources to conduct higher-level studies & 37 & $(62)$ \\
\hline Lack of skills to carry out study & 31 & $(52)$ \\
\hline Lack of support from management & 25 & $(42)$ \\
\hline Unaware of possible ongoing research & 18 & (30) \\
\hline No personal interest & 3 & (5) \\
\hline No ideas as to the possible barriers & 1 & $(2)$ \\
\hline \multicolumn{3}{|l|}{ Factors supporting research involvement } \\
\hline Personal satisfaction & 49 & $(82)$ \\
\hline Opportunity to learn about disease state & 47 & (78) \\
\hline Professional advancement & 42 & (70) \\
\hline Promotion incentive & 20 & (33) \\
\hline Financial reward incentive & 18 & (30) \\
\hline \multicolumn{3}{|l|}{ Perceived benefits of doing research } \\
\hline Improve knowledge & 53 & (88) \\
\hline Fill in knowledge gap & 52 & $(87)$ \\
\hline Personal growth & 48 & $(80)$ \\
\hline Improve patient care & 47 & (78) \\
\hline Variety in job & 44 & (73) \\
\hline Work satisfaction & 40 & $(67)$ \\
\hline \multicolumn{3}{|c|}{ Suggested strategies for conducting future research } \\
\hline Opportunities to join existing teams & 44 & $(73)$ \\
\hline Mentorship program & 42 & (70) \\
\hline Workshops on relevant research topics & 32 & (53) \\
\hline Independent self-study resources & 22 & (37) \\
\hline Videos or webinars & 16 & $(27)$ \\
\hline Other & 7 & $(12)$ \\
\hline
\end{tabular}

and addressing other perceived weaknesses could promote increased research involvement. ${ }^{14}$ Workshops and on-site access to a statistician could also be offered to pharmacists as resources to enhance their expertise in statistical data analysis.

Several barriers have been identified by pharmacists in different settings and various countries. Lack of dedicated time, competing priorities related to workload, and lack of resources to carry out higher-level studies have been common themes. ${ }^{1,25,6,8,9,15,16}$ Few pharmacist positions include research as part of the job description. If increased research activity is expected, then employer support for such activity needs to be improved, through the addition of educational resources and the protection of dedicated research time. A previous study found that secure funding and protected time for conducting research were significant predictors of the number of scientific publications written by pharmacists. ${ }^{17}$

A lower level of management support for research was found in the current study $(42 \%, 25 / 60)$ than in a previous research study, in which $50 \%(105 / 210)$ of respondents believed there was adequate hospital and pharmacy administration support. ${ }^{1}$ Continued support from management is crucial to research success, and studies evaluating pharmacy services could help improve efficiency and maximize appropriate allocation of pharmacy resources.

Opportunities to join existing teams, mentorship programs, and workshops were identified as being most beneficial for engaging pharmacists in future research; pharmacists without prior research exposure favoured these activities more than those with prior experience. A mechanism to offer pharmacists without prior access to established research teams should be explored. Researchers have advocated for the creation of practice-based research networks as a way to promote research culture and mentorship. ${ }^{2,18}$ Pharmacists can form and join such networks to connect and collaborate with other interdisciplinary professionals on various research topics. The proposed benefits of practice-based research networks include increasing community engagement, ensuring the design of robust studies, and facilitating mentorship between pharmacists. ${ }^{2,18,19}$ Relationships between health authorities and faculties of pharmaceutical sciences could also contribute to increased collaboration and research activity.

This study had several limitations. It was not possible to prevent a single individual from completing the survey more than 
once, because the survey link was not tied to individual e-mail addresses. In addition, the response rate was low, with a high proportion of respondents having prior research experience; this may have introduced bias, thus limiting the generalizability of the results. In comparison, a study of intensive care pharmacists across Canada achieved a 66\% (215/325) response rate. ${ }^{1}$ The data collected in the current study reflected self-identified assessments, and were not objectively verified. In particular, the survey lacked a standardized approach for respondents to categorize their current research skills, so respondents were asked to identify their skills on the basis of self-reflection, which may have increased subjectivity and bias in the results and analysis. Those who chose to participate in the study may have been more inclined to be involved in research than nonrespondents, producing a response bias. Given these potential limitations, future research could examine similar issues both before and after implementation of strategies to engage pharmacists in conducting research, and could also examine post-implementation research output.

\section{CONCLUSION}

Pharmacists appear to have a keen interest in participating in clinical research; however, significant barriers and competing workload priorities exist. An improved mechanism for connecting pharmacy staff to existing research teams and creation of a mentorship program are recommended to engage pharmacists in the Lower Mainland Pharmacy Services and to increase their research output.

\section{References}

1. Perreault MM, Thiboutot Z, Burry LD, Rose L, Kanji S, LeBlanc JM, et al. Canadian survey of critical care pharmacists' views and involvement in clinical research. Ann Pharmacother. 2012;46(9):1167-73.

2. Awaisu A, Alsalimy N. Pharmacists' involvement in and attitudes toward pharmacy practice research: a systematic review of the literature. Res Soc Admin Pharm. 2015;11(6):725-48.

3. Carr MB, Divine H, Hanna C, Freeman PR, Blumenschein K. Independent community pharmacist interest in participating in community pharmacy research networks. J Am Pharm Assoc. 2011;51(6):727-38.

4. Elkassem W, Pallivalapila A, Al Hail M, McHattie L, Diack L, Stewart D. Advancing the pharmacy practice research agenda: views and experiences of pharmacists in Qatar. Int J Clin Pharm. 2013;35(5):692-6.

5. Hébert J, Laliberté MC, Berbiche D, Martin E, Lalonde L. The willingness of community pharmacists to participate in a practice-based research network. Can Pharm J. 2013;146(1):4754.

6. Kanjanarach T, Numchaitosapol S, Jaisa-ard R. Thai pharmacists attitudes and experiences of research [abstract]. Res Social Admin Pharm. 2012; 8(6): $558-9$.

7. Awaisu A, Bakdach D, Elajez RH, Zaidan M. Hospital pharmacists' selfevaluation of their competence and confidence in conducting pharmacy practice research. Saudi Pharm J. 2015;23(3):257-65.

8. Peterson GM, Jackson SL, Fitzmaurice KD, Gee PR. Attitudes of Australian pharmacists towards practice-based research. J Clin Pharm Ther. 2009;34(4): 397-405.

9. Simpson SH, Johnson JA, Biggs C, Biggs RS, Kuntz A, Semchuk W, et al. Practice-based research: lessons from community pharmacist participants. Pharmacotherapy. 2001;21(6):731-9.

10. Dowling TC, Murphy JE, Kalus JS, Nkansah NT, Chappell JS, Wiederhold NP, et al. Recommended education for pharmacists as competitive clinical scientists. Pharmacotherapy. 2009;29(2):236-44.
11. Smith JA, Olson KL, Sowinski KM; American College of Clinical Pharmacy. Pharmacy practice research careers. Pharmacotherapy. 2009;29(8):1007-11.

12. Poloyac SM, Empey KM, Rohan LC, Skledar SJ, Empey PE, Nolin TD, et al. Core competencies for research training in the clinical pharmaceutical sciences. Am J Pharm Educ. 2011;75(2):Article 27.

13. Creswell JW. Qualitative inquiry and research design: choosing among five approaches. Thousand Oaks (CA): Sage Publications; 2007.

14. Pinelli NR, Sikora AN, Witherspoon LA, Rao KV, Rhoney DH. Impact of pharmacy residency research training on residents' actual versus perceived ability and interest to identify and solve practice-related problems. J Pharm Pract. 2016;29(4):421-6.

15. Sultana $\mathrm{K}, \mathrm{Al}$ Jeraisy $\mathrm{M}, \mathrm{Al}$ Ammari M, Patel R, Zaidi STR. Attitude, barriers and facilitators to practice-based research: cross-sectional survey of hospital pharmacists in Saudi Arabia. J Pharm Policy Pract. 2016;9:4.

16. Stewart D, Al Hail M, Abdul Rouf PV, El Kassem W, Diack L, Thomas B, et al. Building hospital pharmacy practice research capacity in Qatar: a cross-sectional survey of hospital pharmacists. Int J Clin Pharm. 2015; 37(3):511-21.

17. Lelièvre J, Bussières JF, Lebel D, Prot-Labarthe S. Predictors of publication productivity among hospital pharmacists in France and Quebec. Am J Pharm Educ. 2011;75(1): Article 17.

18. Farland MZ, Franks AS, Byrd DC, Thomas JL, Suda KJ. Development of a primary care pharmacist practice-based research network. Currents Pharm Teach Learn. 2012;4(2):150-4.

19. Fagan SC, Touchette D, Smith JA, Sowinski KM, Dolovich L, Olson KL, et al. The state of science and research in clinical pharmacy. Pharmacotherapy. 2006;26(7):1027-40.

Robin Lee, BSc, is a student in the Faculty of Pharmaceutical Sciences (Class of 2018), The University of British Columbia, Vancouver, British Columbia.

Karen Dahri, BSC, BSc(Pharm), PharmD, ACPR, is a Clinical Pharmacotherapeutic and Research Specialist in Internal Medicine, Pharmaceutical Sciences, Vancouver General Hospital, and is also an Assistant Professor (Partner) with the Faculty of Pharmaceutical Sciences, The University of British Columbia, Vancouver, British Columbia.

Tim T Y Lau, PharmD, is a Clinical Supervisor and Pharmacotherapeutic Specialist in Infectious Diseases, Pharmaceutical Sciences, Vancouver General Hospital, and is also a Clinical Professor with the Faculty of Pharmaceutical Sciences and an Associate Member in the Division of Infectious Diseases, Faculty of Medicine, The University of British Columbia, Vancouver, British Columbia.

Stephen Shalansky, BSC(Pharm), ACPR, PharmD, FCSHP, is Clinical Coordinator of the Pharmacy Department, Providence Healthcare, Lower Mainland Pharmacy Services, and is a Clinical Professor with the Faculty of Pharmaceutical Sciences, The University of British Columbia, Vancouver, British Columbia. He is also the Editor of the Canadian Journal of Hospital Pharmacy.

\section{Competing interests: None declared.}

\section{Address correspondence to:}

Dr Karen Dahri

Pharmaceutical Sciences

Vancouver General Hospital

855 West 12th Avenue

Vancouver BC V5Z 1M9

e-mail: Karen.Dahri@vch.ca

Funding: None received.

Acknowledgements: The authors thank Anthony Tung and Dr Angus Kinkade, Clinical Pharmacy Specialists, Medication Use Evaluation, Fraser Health Authority, for their contributions to the study design and to drafting and revision of the study questions and the manuscript. 